\title{
Performance Evaluation of Acid Stimulation Models for Optimum Oil Production from Sandstone Reservoir using Mud Acid (HCL-HF Blend)
}

\author{
OBURU, P. ${ }^{1}$, AKPA, J. G' ${ }^{2}$, OJONG, O. E 3* $^{*}$ \\ 1-2 Department of Chemical/Petrochemical Engineering Rivers State University, Nkpopu-Oroworukwo, Port \\ Harcourt Rivers State, Nigeria \\ ${ }^{3}$ Chemical Engineering Department University of Calabar, Cross River State, Nigeria
}

*Corresponding Author: OJONG, O. E, Chemical Engineering Department University of Calabar, Cross River State, Nigeria

\begin{abstract}
In this work, an analysis of acid stimulation models is presented with a view to ensuring optimal production from the ideal sandstone reservoir. The model results were implemented with MATLAB solver and the results discussed accordingly. The acid treatment type used is matrix acidizing with a mud-acid formulation. The results actually indicated that the performance of damaged wellbore reservoir (sandstone) can be revived in other to increase its maximum productivity by the application of well-studied properties of the reservoir and correct formulations of acids proportion ( $\mathrm{HCl}$ and $\mathrm{HF}$ ) for the stimulation process. It should be noted that the stimulation of the matrix acidizing process (stimulation) was based on the physiochemical properties of the reservoir for avoidance of reactions and more damages that might cause. The results agree with the trends examined from known literatures and industrial practices. Curated results from fundamental design parameters and economic variables show that the greater the damage penetration into the reservoir, the higher the cost of stimulating such reservoirs via acid treatments as a result of increased injected volume of acid into the reservoir. Further analysis also showed that productivity ratio can be remarkably improved by increasing the effective reservoir radius which represents the primary objective of an acid treatment job design
\end{abstract}

Keywords: Injection Rate, Matrix Acidizing, Mud-Acid, Radius of Damage, Surface Pressure

\section{INTRODUCTION}

Stimulation is performed on a well to increase or restore production. Sometimes, a well initially exhibits low permeability and stimulation is employed to commence production from the reservoir. However, in most of the cases, stimulation is used to further encourage permeability and flow from an already existing well and also increase production thereby improving the flow of Hydrocarbons from the reservoir (Energy today, 2014; www.norshore.com; www.slb.com)

Acidizing technique has been identified by several literatures as a well stimulation treatment an acid is pumped into the reservoir in an attempt to enhance production and eliminate skin. Well acidizing is achieved by pumping acid into the well to dissolve limestone, dolomite and calcite cement between the sediment grains of the reservoir rocks (Hajime \& Fulhorst, 2019). The two types of acid treatments currently used in the industry are matrix acidizing and fracture acidizing. In matrix acidizing, the acid is pumped at pressures lower than reservoir fracture pressure to into the reservoir to dissolve the sediments and mud solids that are inhibiting the permeability of the rock, enlarging the natural pores of the reservoir and stimulating flow of hydrocarbons. In contrast, fracture acidizing uses highly pressurized schemes to pump acid into the reservoir at pressures above reservoir fracture gradients. As a rule, acidizing is commonly performed on new wells to maximize their initial productivity and on aging wells to restore productivity and maximize the recovery of the energy resources (Mahajan et al, 2006). Hence, acid treatment is often used to optimize production (via permeability enhancement) against potential formation damage and to ensure positive return on investment from well establishment cost (Almarri, 2015; Ziauddin et al, 1999).

Conventionally, two types of acids commonly in use for well stimulation purposes include $\mathrm{HCl}$ and $\mathrm{HF}$. These are used either in a single phase or blended mixtures known as mud acids. However, $\mathrm{HCl}$ has 
been more generally used across the industry for well stimulation studies. Ziauddinet al (1999) has noted the choice of $\mathrm{HCl}$ in well stimulation is due to its ability to readily dissolve carbonates, limestones and dolomites rocks. It can also combine with a mud acid (HCl-HF blend) or simply, HF that can be used to dissolve quartz, sand and clay materials. One major setback to acid treatments is its adverse effect on the well system and production facilities. Hence, to considerably guarantee the integrity of the well system, inhibiting additives are usually introduced to prohibit the attack of the acid on the steel casing environments. The potential for the formation of gels or precipitation of irons that can clog the reservoir pores thereby increasing the already developed skin is usually done using a sequestering agent (Quinn et al, 2003). The end of acid treatment job is often marked by a process called "backflushing" in which the used acid and removed sediments are washed out of the well.

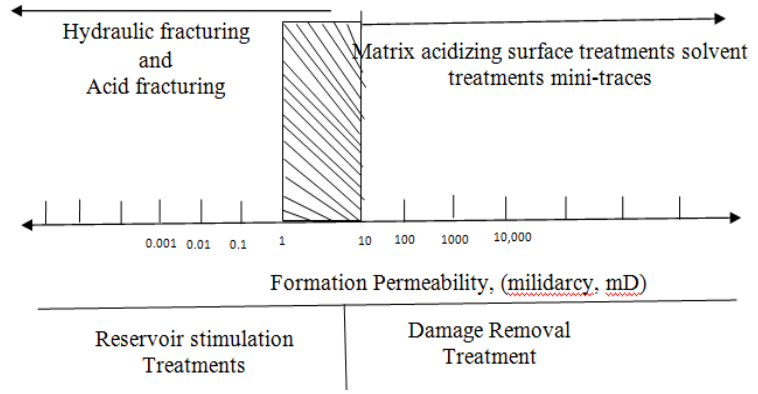

Fig1. Spectrum of Stimulation Treatment Applicability (Garcia et al, 2011)

Both hydraulic fracturing and acid treatments (matrix acidizing and fracture acidizing) share common objective of reservoir performance enhancement via removal or reduction in skin. However, the specific choice of the desired technique often depends on the formation permeability chart and specific objective as shown in Fig 1. Generally, formations with high permeability (with several hundred $\mathrm{mDs}$ ) often associated with unproductive wells as a result of severe formation damage securing in sandstone, such well can be stimulated for optimality with the application of acidizing technique which are capable of removing near wellbore damage, preferred to hydraulic fracturing (Porte, 1989). The development of fractures in a reservoir affects the flow convergence profile. This is illustrated in Fig 2 below.

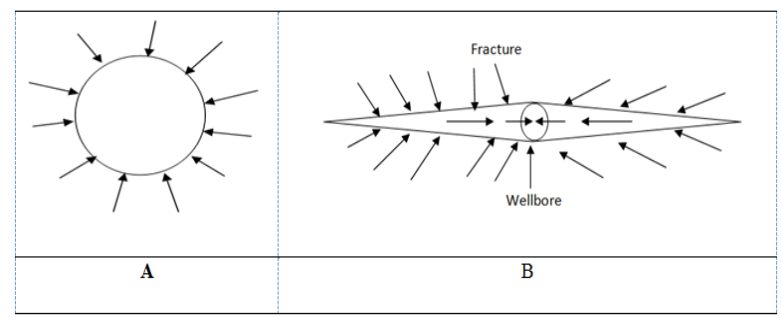

Fig2-(A): Flow to Un-fractured Well Converges at Wellbore; (B): Flow on Fractured well is Linear to Fracture (Hekim et al, 1982)

The success of the operation depends on the conductivity of the hydraulic fracture and retained the conductivity of the hydraulic fracture. This depends largely on the design and execution of the fracturing treatment. After fracture occurs, the fracture continues to grow at a point where the fracture can accept a propping agent and added to the fracture as shown in Fig 3 (Ben-Naceur \& Economides, 2005).

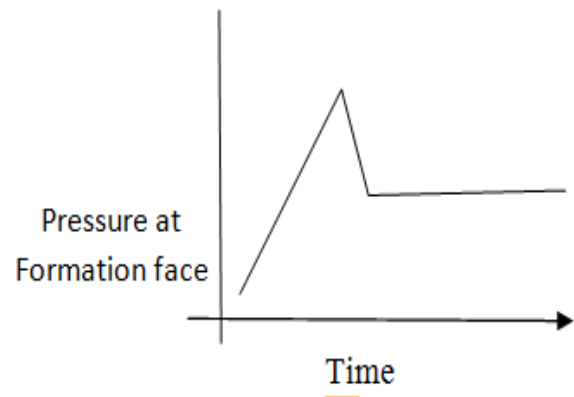

Fig3. Introduction Time of Proppantto Fracture (Ben-Naceur \& Economides, 2005) 
Proppant (Materials used in hydraulic fracturing extraction) such as resin-coated sand, and ceramic beads are often used for acid stimulation process. Reservoir clean-up involves the removal of fractured fluid from the formation to initiate the reservoir fluid production.

Several models have been presented by various authors in assessing the performance of acid fracturing. In this study, some of these are specifically applied in order to analyze the performance of acid treatment of a sandstone reservoir using mud acid.

\section{Methodology}

2.1. Estimating the Fundamental Acid Treatment Design Parameters (Economides \& Nolte ,2000; Sevougian et al, 1992; Shchecheter \& Gidley, 2008)

The well screening technique used in this work assumed that accurate well diagnosis has been performed with well test data and matched accordingly with acidizing, gravel packing and recompletion. It is also assured that the case study well can be successfully acidized, recompleted or gravel packed. The treatment models presented in this section are to be used for the stimulation treatment design. The choice of which model to use is dependent on the nature of well problem diagnosed and the result of the screening module.

In the absence of instantaneous shut-in pressure value, Economides \& Nolte (2000) model has been used to estimate reservoir fracture gradient as shown in Eq. 1 below.

$\mathbf{g}_{f}=\propto+\left(\mathbf{g}_{\mathrm{ob}}-\propto\right) \frac{\mathbf{P}_{\mathbf{r}}}{\mathbf{D}}$

where $\mathrm{g}_{f}=$ Fracture gradient, $\mathrm{kg} / \mathrm{cm} ; \propto=0.33-0.50 \mathrm{~kg} / \mathrm{cm} ; \mathrm{g}_{\mathrm{ob}}=$ overburden gradient $(1.0 \mathrm{Kg} / \mathrm{cm}$ for formation depth, D less than $3700 \mathrm{~m}$ or $0.01 \mathrm{Kg} / \mathrm{cm}$ for depth greater than $3700 \mathrm{~m}$ (Sevougian et al, 1992); $\mathrm{P}_{\mathrm{r}}=$ Reservoir pressure, $\mathrm{kg} / \mathrm{cm}^{2} ; \mathrm{D}=$ Depth of formation, $\mathrm{m}$.

The corresponding optimal injection rate at $\mathrm{g}_{\mathrm{f}}$ is given in Eq. 2 below.

$q_{\text {imax }}=\frac{4.917-10^{-6} k \mathfrak{h}\left[\left(g_{f} D\right)-\Delta P_{\text {safe }}-P_{r}\right]}{\mu B\left(\operatorname{In}\left(\frac{r_{e}}{r_{w}}\right)+S\right)}$

Where; $q_{\text {imax }}=$ injection rate, $\mathrm{m}^{3} / \mathrm{s} ; k=$ effective permeability of the undamaged formation, $\mathrm{mD}$ (Millidarcy); $h=$ net pay thickness, $\mathrm{m} ; \Delta P_{\text {safe }}=$ Safety margin for the pressure, $\mathrm{kg} / \mathrm{cm}^{2}$ (usually 200 to $500 \mathrm{psi}) ; \mu=$ viscosity of the injected fluid, $\mathrm{kg} / \mathrm{cm}^{2} ; r_{e}=$ drainage radius, $\mathrm{m} ; r_{w}=$ wellbore radius, $\mathrm{m} ; S$ $=$ Skin factor; $\beta=$ formation volume factor (equals 1 for incompressible fluids).

The maximum theoretical acid pump rate during treatment occurs at $\mathrm{s}=0$. For a Newtonian fluid, the coil tubing friction pressure at pump rates $\leq 9 \mathrm{bbl} / \mathrm{min}$ can be calculated from the Shchecheter \& Gidley (2008) model in Eq. 3 as follows.

$\mathrm{g}_{\text {friction }}=\frac{0.518 \gamma^{0.79} \times \mathcal{q}^{1.79} \times \mu^{0.207}}{d^{4.79}}$

where; $\mathrm{g}_{\text {friction }}$ frictional pressure, $\mathrm{psi} / \mathrm{ft} ; \gamma=$ specific gravity of the acid $\left(\right.$ or density of acid in $\left.\mathrm{gcm}^{3}\right) ; q$ $=$ pump rate, $\mathrm{bbl} / \mathrm{min} ; d=$ Diameter of pipe, $\mathrm{m}$. At pump rates greater than $9 \mathrm{bbl} / \mathrm{min}$, the coil tubing frictional pressure is ignored.

One of the very important design parameter for a successful acid treatment job is the maximum surface pressure. This is calculated by balancing the existing pressure gradients in the well system during acid treatment as shown in Eq. 4. With the coil tubing friction ignored, Eq.4 reduces to Eq.5.

$$
\begin{aligned}
& P_{s, \text { max }}=\left(g_{\mathrm{f}}+g_{\text {friction }}-g_{\text {acid }}\right) D \\
& P_{\mathrm{s}, \max }=\left(g_{\mathrm{f}}-\mathbf{g}_{\text {acid }}\right) D
\end{aligned}
$$

\subsection{Mud Acid Economic Variables During Well Treatment}

The economy of an acid treatment job often depends on the estimated volume of acid for use. This usually based on empirical assumption that the required acid volume equals the pore volume assumed to be damaged and that the acid phase flows through the porous uniformly and remains stable. From the works of Shchecheter \& Gidley (2008), the maximum mud acid volume can be estimated using Eq.6.

$\mathrm{V}_{\mathrm{m}}=7.48\left[\pi \emptyset\left(r_{s}^{2}-r_{w}^{2}\right)\right]$ 
Performance Evaluation of Acid Stimulation Models for Optimum Oil Production from Sandstone Reservoir using Mud Acid (HCL-HF Blend)

Where; $\mathrm{V}_{\mathrm{m}}=$ volume of mud acid, $\mathrm{m}^{3} / \mathrm{s} ; \varnothing=$ porosity, fraction; $r_{\mathrm{s}}=$ damage radius (displaced section), $\mathrm{m}$ For high $\mathrm{HCl}$ per moderation injection; then Eq.6 can be modified as follows;

$V_{H C l} \frac{7.48 \pi(1-\varnothing) X_{H C L\left(r_{S}^{2}-r_{W}^{2}\right)}}{\beta}$

Where; $\mathrm{V}_{\mathrm{HCL}}=$ volume of $\mathrm{HCl}$ required $\mathrm{m}^{3} / \mathrm{s} ; \mathrm{X}_{\mathrm{HCL}}=$ fraction of the bulk rock dissolved by $\mathrm{HCl}(\mathrm{aq})$; $\beta=$ Coefficient that dissolved

Hence, with the equations (6) and (7), the total cost of acid used can be estimated from Eq.8.

$\mathrm{C}_{\mathrm{s}}=\mathrm{C}_{\mathrm{sm}} \mathrm{V}_{\mathrm{h}}$

Where; $\mathrm{C}_{\mathrm{sm}}=$ cost of acid used per unit volume, $\$ / \mathrm{gal}$

Since it is difficult to increase the permeability of sandstone due to limitations in the reaction kinetics, $\left(\mathrm{r}_{\mathrm{i}}\right)$, the stoichiometry and economics. The formation productivity in this research work is determined using set of reservoir parameters which are inverse of flow efficiency, at steady state using predicted models from Economides and Nolte (2000);

$\mathrm{F}_{\max }=\frac{\operatorname{In}\left(\frac{0.472 \mathrm{r}_{\mathrm{e}}}{\mathrm{r}_{\mathrm{w}}}\right)+S}{\operatorname{In}\left(\frac{0.472 \mathrm{r}_{\mathrm{e}}}{\mathrm{r}_{\mathrm{w}}}\right)}$

where: $\mathrm{F}_{\max }=$ Max productivity ratio; $\mathrm{S}=$ skin factor; $\mathrm{r}_{\mathrm{w}}=$ wellbore radius, $\mathrm{m} ; \mathrm{r}_{\mathrm{e}}=$ reservoir radius, $\mathrm{m}$ Van Everdingen and Hurst (1949) defined the skin effect as;

$\mathrm{S}=\left(\frac{K}{K_{d}}-1\right) \operatorname{In} \frac{r_{d}}{r_{w}}$

Equation (10) in a dimensionless number and reflects the changing permeability due to damage, $\mathrm{k}_{\mathrm{d}}$ at a distance, ${ }_{\mathrm{r}} \mathrm{d}$ with steady state pressure difference.

For damage well, $k_{d}<k$ and $s>0$ and also if $k_{d}>k, s<0$ and the well is stimulated, for $s=0$, the nearwellbore permeability equal to the original reservoir permeability.

For lack of production log data, Frick \& Economides (1993) developed skin effect expression which are analogous to the Hawkins formula:

$\mathrm{S}_{\mathrm{eq}}=\left(\frac{K}{K_{d}}-1\right) \operatorname{In}\left[\frac{1}{\mathrm{I}_{\mathrm{ani}+1}}\right] \sqrt{\frac{4}{3}\left(\frac{\alpha_{S H, \max }^{2}}{r_{w}^{2}}+\frac{\alpha_{S H, \max }}{r_{w}}+1\right)}$

Where; $S_{\text {eq }}=$ Equivalent skin effect; $\mathrm{I}_{\text {ani }}=$ index of a anisotropy

\section{RESUltS AND DiSCUSSION}

The use of $\mathrm{HCl}$ as an Acidizing agent for the stimulation of sandstone reservoir to improve permeability and reduces wellbore damage helps to increase productivity of the oil and gas has been carried out. The matrix acidizing models developed following the step wise approach were run using MATLAB program and the following results were generated as shown in tables (Appendix I) and Figures (4.1-4.20). The model solutions were implemented with input parameters generated from Ugbenyen (2012).

Table1. Input parameters for the simulation (Ugbenyen, 2012)

\begin{tabular}{|c|c|c|}
\hline Parameters & Symbol & Value \\
\hline Average reservoir press, & $\mathrm{Pr}$ & $26545 \mathrm{KPa}$ \\
\hline Drainage Radius & $\mathrm{r}_{\mathrm{e}}$ & $304.8 \mathrm{~m}$ \\
\hline Wellbore Radius, & $\mathrm{r}_{\mathrm{w}}$ & $0.0944 \mathrm{~m}$ \\
\hline Net-pay thickness & $\mathrm{H}$ & $20.78736 \mathrm{~m}$ \\
\hline Depth of formation & $\mathrm{D}$ & $3688.08 \mathrm{~m}$ \\
\hline Damage zone radius & $\mathrm{r}_{\mathrm{d}} \mathrm{r}_{2,}$ & $1.83 \mathrm{~m}$ \\
\hline Undamaged Reservoir permeability & $\mathrm{K}$ & $1.05 \mathrm{~Pa} . \mathrm{s}$ \\
\hline Damage zone permeability & $\mathrm{K}_{\mathrm{d}}$ & $0.1 \mathrm{~Pa} . \mathrm{s}$ \\
\hline Porosity & $\varnothing$ & 0.25 \\
\hline Formation volume factor & $\beta$ & 1.159 \\
\hline Acid hydrostatic Gradient & $\mathrm{g}_{\mathrm{od}}$ & 10.1792 \\
\hline Specific Gravity of acid & $\mathrm{S} . \mathrm{G}$ & 1.04 \\
\hline
\end{tabular}


Performance Evaluation of Acid Stimulation Models for Optimum Oil Production from Sandstone Reservoir using Mud Acid (HCL-HF Blend)

\begin{tabular}{|c|c|c|}
\hline Viscosity of Injection Rate & $\mu$ & $5.7 \mathrm{E}-4 \mathrm{~Pa} . \mathrm{s}$ \\
\hline Pump rate & $\mathrm{Q}$ & $5.30 \mathrm{E}-3 \mathrm{~m}^{3} / \mathrm{s}$. \\
\hline Injection safety pressure & $\mathrm{P}_{\text {safe }}$ & $1378.95 \mathrm{KPa}$ \\
\hline Diameter of coil tubing & $\mathrm{d}_{\mathrm{ct}}$ & $1.75 \times 10^{-3} \mathrm{~m}$ \\
\hline Cost of Acid & $\mathrm{C}_{\mathrm{A}}$ & $\$ 30 \mathrm{pergal}$ \\
\hline Current production rate & $\mathrm{q}_{\mathrm{e}}$ & $500 \times 6.28 \mathrm{~m}^{3} / \mathrm{day}$ \\
\hline Exponential decline rate & $\mathrm{K}_{\mathrm{r}}$ & 1 day \\
\hline Duration of stimulation & $\mathrm{t}_{\mathrm{s}}$ & $27.144 \mathrm{KPa} / \mathrm{m}$ \\
\hline Overburden gradient & $\mathrm{g}_{\mathrm{ab}}$ & $\mathrm{d}$ \\
\hline
\end{tabular}

The Fig 4 below shows a plot of volume of acid used versus radius of damage. The result shows that as more acid is being used up to remedy the situation so as to increase oil and gas productivity, it goes through the penetrated damage radius to dissolves the scales or blockages that must have cause the damage. From the graph, $200 \mathrm{~cm}^{3}$ of acid was used up for acid acidizing of the wellbore zone at damage radius of $300 \mathrm{~mm}$ and increases to $9000 \mathrm{~cm}^{3}$ of acid at radius of damage $1200 \mathrm{~mm}$. However, from the work of Rae \& Lullo, (2003), use of HCL is perfect as only very low volume of acid is needed for efficient acid stimulation and thus reduces cost of acid usage since the higher the volume of acid, the more expensive the application of the process for reservoir damage maintenance. From the plot in Fig 5 , higher radius of damage will need more volume of acid to be used and thus making the stimulation process relatively more expensive. In Figure 5, the variation profile of maximum surface pressure versus frictional pressure is shown. The relationship gives a concern for designing wellbore acid treatment of reservoirs with coil tubing unit. Excessive friction in the system (which is directly related to the acid column hydrostatics) can affect the delivery of the acid at the desired pressure and rate. This result also validates the industrial practice of "low volume- high pressure" schemes for achieving certain hydraulic target. This is also the reason why inhibitors are usually introduced in the acid medium to minimize its attack on the casing environment that can be greatly influenced by excessive frictional stresses created.

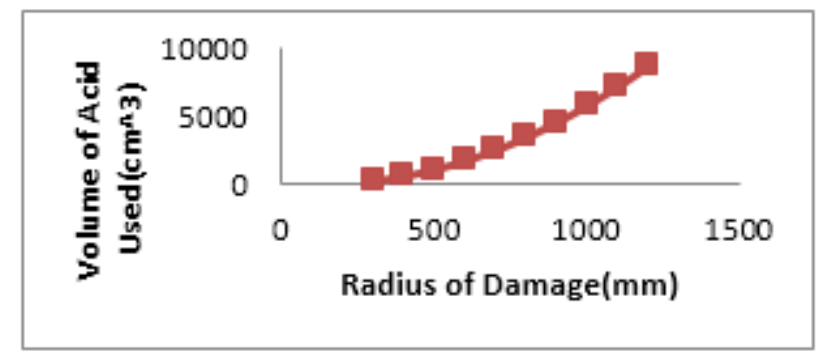

Fig4. Profile Variation of Volume of Acid used versus Radius of Damage

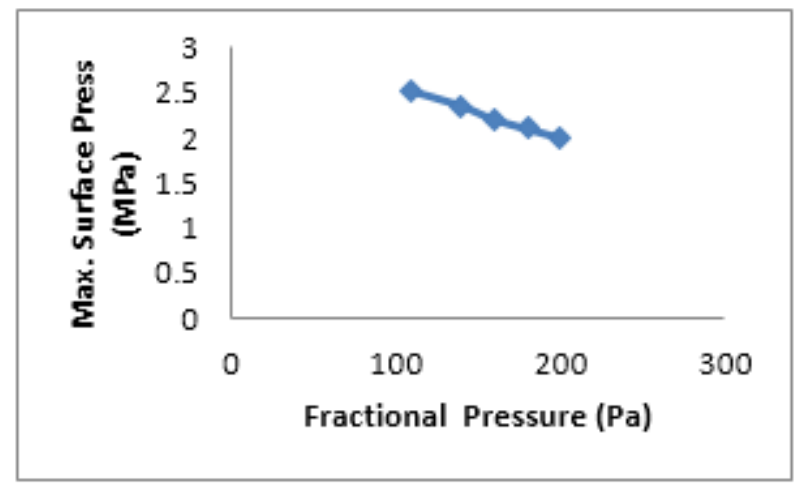

Fig5. Variation profile of Maximum Surface Pressure versus Frictional Pressure

The result shown in Fig6 below demonstrates the relationship between the injection rates with wellbore radius. It conforms to most processes involving fluid injection into a porous media through an opening (wellbore). As clearly shown, it is typical parabolic curve. It can be predicted that the more the wellbore radius, the lower the injection rate and insignificant of the process to reservoir revival. The Injection rate of acid into the damage zone reduces with wellbore radius as shown in Fig 6 below $1195 \mathrm{~m}^{3} / \mathrm{s}$ was injected at $r_{w}=600 \mathrm{~mm}$ and reduces to $1163 \mathrm{~m}^{3} / \mathrm{s}$ as $r_{w}$ increases to $1200 \mathrm{~mm}$. This result and profile agrees with literature results and profiles on acid stimulation works by Economides a\& Nolte, (2000) and other relevant literatures for such research works. In Fig 7 above, the volume of acid used increases as the 
damage radius, say, at $r_{s}=1.8 \mathrm{~m}$, the $V_{\text {aciid }}=10 \mathrm{~m}^{3}$ and increases to $750 \mathrm{~m}^{3}$ as $r_{\mathrm{s}}$ becomes $11 \mathrm{~m}$. The relationship between the volumes of mud acid used with damage radius is necessary because it provides us with information on optimal operation of the process. As shown, damage radius between the ranges of $1 \leq r_{d} \leq 3.5 m$ will be suitable for Acid stimulation in other to cause the damage reservoir performed again optimally as when it was at its young age. It is expected from literatures that the volume of acid used for acidizing should be more when the damage radius is large. So with this trend, the result and profile of this research work agrees with literature according to Ugbenyen (2012).

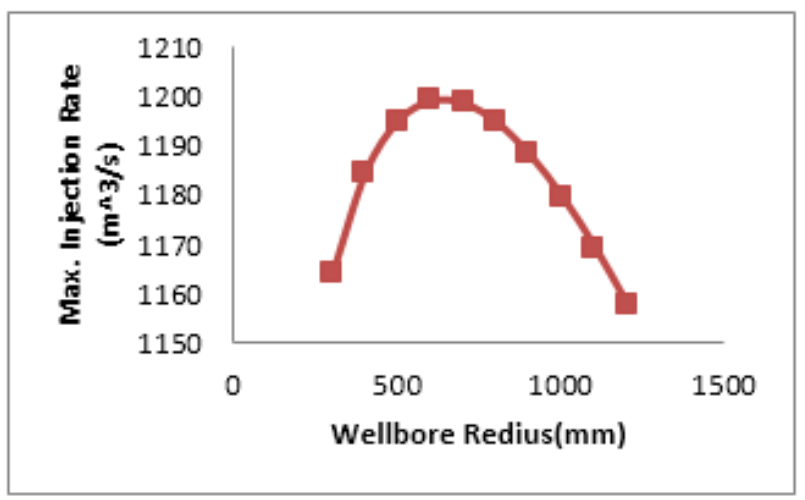

Fig6. Variation plot of Maximum Injection Rate versus Wellbore Radius

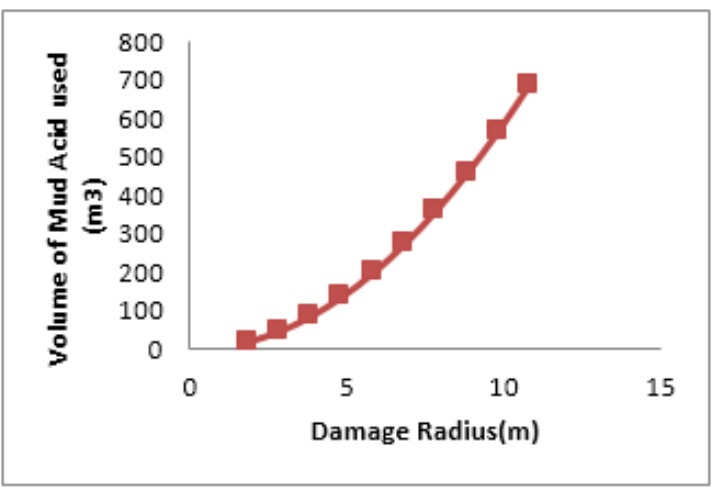

Fig7. Variation of Volume of Mud Acid used versus Damage Radius

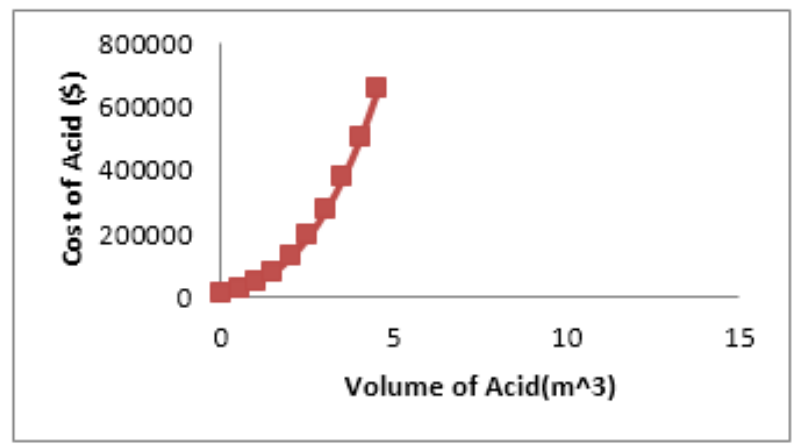

Fig8. Cost of Acid versus Volume of Acid Used

The result shown in Fig 6 below demonstrates the relationship between the injection rates with wellbore radius. It conforms to most processes involving fluid injection into a porous media through an opening (wellbore). As clearly shown, it is typical parabolic curve. It can be predicted that the more the wellbore radius, the lower the injection rate and insignificant of the process to reservoir revival. The Injection rate of acid into the damage zone reduces with wellbore radius as shown in Fig 6 above. $1195 \mathrm{~m}^{3} / \mathrm{s}$ was injected at $r_{w}=600 \mathrm{~mm}$ and reduces to $1163 \mathrm{~m}^{3} / \mathrm{s}$ as $r_{w}$ increases to $1200 \mathrm{~mm}$. This result and profile agrees with literature results and profiles on acid stimulation works by Economides \& Nolte, (2000) and other relevant literatures for such research works. In Fig 7 above, the volume of acid used increases as the damage radius, say, at $r_{s}=1.8 \mathrm{~m}$, the $V_{\text {aciid }}=10 \mathrm{~m}^{3}$ and increases to $750 \mathrm{~m}^{3}$ as $\mathrm{r}_{\mathrm{s}}$ becomes $11 \mathrm{~m}$. The relationship between the volumes of mud acid used with damage radius is necessary because it provides 
us with information on optimal operation of the process. As shown, damage radius between the ranges of $1 \leq r_{d} \leq 3.5 \mathrm{~m}$ will be suitable for Acid stimulation in other to cause the damage reservoir performed again optimally as when it was at its young age. It is expected from literatures that the volume of acid used for acidizing should be more when the damage radius is large. So with this trend, the result and profile of this research work agrees with literature according to Ugbenyen (2012).

The variation of maximum productivity ratio with reservoir radius is shown in the profile of Fig 9 . The greater the reservoirs radius, the maximum the production and this will only happen with a threshold value say $300 \mathrm{~mm}$ as shown in Fig 9. After such threshold value, increase in $r_{e}$, increase in production ratio and increase in production as shown from Fig 9 . At $r_{e}=300 \mathrm{~mm}, F_{\max }=0.686$ and increases to $F_{\max }$ $=0.708$ as $r_{e}-500 \mathrm{~m}$. Maximum productivity depends on reservoirs radius ranges from $300-1200 \mathrm{~mm}$, this is what acid stimulation performance is needed to achieve and the values range favours the process as shown in works of Economides \& Nolte, (2000); Shchecheter \& Gidley, (2008) and Pitot \& Lietard, (1987) etc. Hence, the generated results are within conservative literatutre. From Fig 10, it is shown that higher values of anisotropy index resulted to lower values of equivalent skin effect. Thus equivalent skin effect is important as lower values makes performance of reservoir efficient and effective thereby increase oil and gas productivity from underperformed damage reservoir which has become revived and stimulated due to acid acidizing process taking place (Frick \& Economics, 1993). This expected trend compared with Fig. 8 means the research results are good and provides adequate information for the stimulation process.

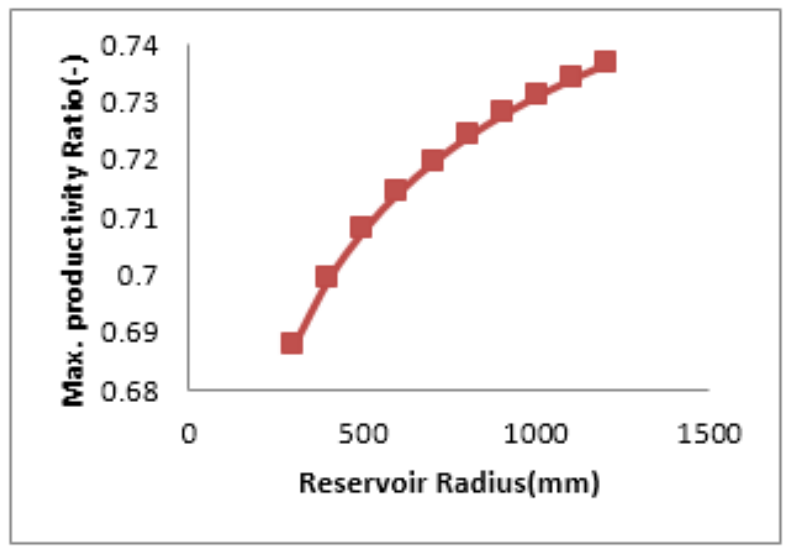

Fig9. Variation of Maximum Productivity Ratio with Reservoir Radius

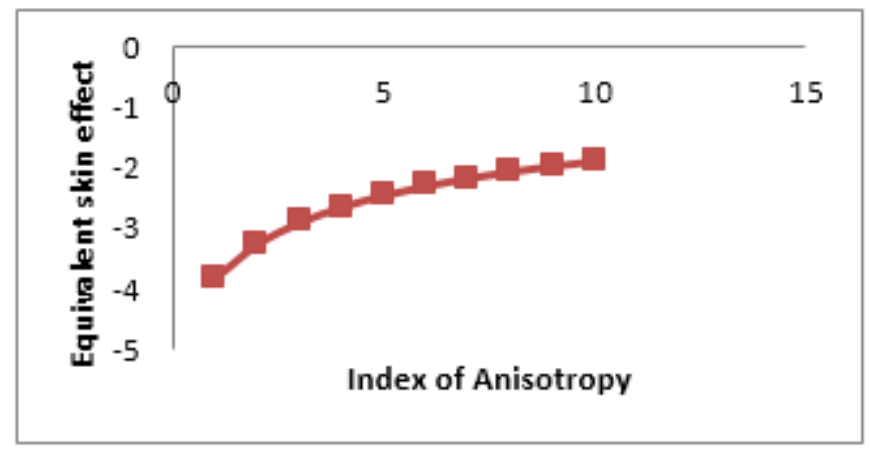

Fig10. Equivalent Skin Effect versus Index of Anisotropy

\section{CONCLUSiON}

This research seeks a method to quantify stimulation benefits obtained from sandstone reservoir and apply the results to grade economically profitable reservoir. To achieve this, a design model was developed for matrix acidizing of sandstone reservoir using MUD ACID based on works from Shchecheter \& Gidley (2008) and Economides \& Nolte (2000). The models developed were resolved numerically using MATLAB and results generated for discussion and analysis. The performance of models used in this study with the mud acid (HCl-HF blend) for sandstone reservoir stimulation has been analyzed. The analysis represented a conventional practice in the oil industries and contributes to better understanding of academic and engineering principles of acid treatment of reservoirs necessary 
for the modification, prediction of future prospects and field re-implementation to increase and enhance productivity. The following recommendations are highlighted for additional research area to improve the methods and models developed.

- The models developed should be used to quantify stimulation gains obtainable from stimulation decision once the well has been matched for matrix acidizing.

- For effective usage of models developed, it is recommended that the least operating cost, federal and state taxes be considered before stimulation.

\section{REFERENCES}

[1] Almarrl, H. M (2015). Analysis of Critical Parameters Affecting the Formation of Wormhole in Acid Stimulation of Carbonate Formations. A Master's Thesis, Energy and Mineral Science, Pennsylvania State University.

[2] Ben-Naceur, K \& Economides, M. J (2005). The Effectiveness of Acid Fractures and their Production Behavior, SPE paper 18536.

[3] Economides, M. J \& Nolte, K. G (2000). Reservoir Stimulation, $3^{\text {rd }}$ Edition. New York: Willey, Chapter 1:1-12.

[4] Economides, M. J \& Nolte, K. G. (2000). Reservoir Stimulation, $3^{\text {rd }}$ Edition, New York: Wiley, Chapter 18, 24-25.

[5] Frick, T. P \& Economides, M. J. (1993). Horizontal Well Damage Characterization and Removal, SPE Production and Facilities 8 (1): 15-22.

[6] Garcia, S., Fraces, E. \& Davila, L. (2011).Revolutionary Matrix Stimulation Process in Offshore Mexico using Coiled Tubing Equipped with optical Fibres (CT-EOF) and Distributed Temperature Survey (DTS). Well Intervention Conference and Exhibition, the Worldwides, Texas, USA.

[7] Hajime, E. \&Fulhorst, M (2019). Acidizing EP-ZA Tougas oilfield solution GMBH, Weismuellerstrasse: Germany.

[8] Hekim, Y, Fogler, H.S \&Melune, C.C. (1982). The Radial Movement of Permeability Fronts and Multiple Reaction Zones in Porous Media, Journal of Petroleum Technology, 99-107.

[9] Mahajam, M., Pasikki, R.G., Gilmore, T.G., Riedal, K.L \&Steinback, S.L. (2006). Successes Achieved in Acidizing of Geothermal wells in Indonesia, SPE Asia pacific oil \& Gas Conference and Exhibition, society of Petroleum Engineers: Australia

[10] Porter, K. E (1989).An Overview of formation Damage.Journal of Petroleum Technology, 41 (8). 1224.

[11] Quinn, M.A., Lake, L.W., Shchecheter, R. S \& Robert, S (1997). Designing Effective Sandstone Acidizing Treatment through Geochemical Modeling, SPE 38173 presented at the European Formation Damage Conference (1997), The Hague.

[12] Rae, P. \& Lullo, G. (2003).Matrix Acid stimulation. A review of the stat-of the-Art paper SP"E 82266 presented at the 2003 SPE European formation Damage conference. The Hagwe, 13-14 May.

[13] Sevougian, S.D., Lake, L.W \& Schechter, R.S (1992). A New Geochemical Simulator to Design more Effective sandstone Acidizing Treatment, SPE paper 24780.

[14] Shchecheter, R. S. \& Gidley, J.L. (2008). The change in pore size Distribution from surface Reactions in Porous Media, AICHE Journal of Petroleum Technology 15:339-350.

[15] Ugbenyen, B. O (2012).An approach to stimulation candidate selection and optimization.AnM.Sc Thesis in Petroleum Engineering, African University of Science and Technology, Abuja.

[16] Van Everdingen, A. F \& Hurst, W (1949).The Application of the Laplace Transformation to flow problems in Reservoirs.Trans, AIME, 186,305-324.

[17] Ziauddin, M., Berndt, O. \& Robert, J. (1999). An improved sandstone acidizing model: The importance of secondary and Tertiary Reactions, Paper SPE 54728 presented at the SPE European formation Damage conference, The Hague, the Netherlands, $31^{\text {st }}$ May $-1^{\text {st }}$ June.

Citation: OJONG, O. E, et.al, "Performance Evaluation of Acid Stimulation Models for Optimum Oil Production from Sandstone Reservoir using Mud Acid (HCL-HF Blend)", International Journal of Petroleum and Petrochemical Engineering, 6(3), pp. 13-20. DOI: https:// doi.org/10.20431/2454-7980.0603002

Copyright: () 2020 Authors, this is an open-access article distributed under the terms of the Creative Commons Attribution License, which permits unrestricted use, distribution, and reproduction in any medium, provided the original author and source are credited. 